\title{
The efficacy of endobronchial blocker "EZ-blocker" for selective lobar ventilation: case report
}

\author{
Michela Galatà ${ }^{1,2}$, Paraskevas Lyberis ${ }^{3}$, Agnese Bisciaio ${ }^{1,2}$, Edoardo Ceraolo ${ }^{1}$, Giulio L. Rosboch ${ }^{1}$, \\ Enrico Ruffini ${ }^{2,3}$, Francesco Guerrera ${ }^{2,3}$ \\ ${ }^{1}$ Department of Anesthesia, Intensive Care and Emergency, Città Della Salute e Della Scienza Hospital, Turin, Italy; ${ }^{2}$ Department of Surgical \\ Science, University of Torino, Turin, Italy; ${ }^{3}$ Department of Thoracic Surgery, Azienda Ospedaliera Universitaria Città Della Salute e Della Scienza \\ di Torino, Turin, Italy \\ Correspondence to: Francesco Guerrera, MD. Department of Surgical Science, University of Torino, Corso Dogliotti, 1410126 Turin, Italy. \\ Email: fra.guerrera@gmail.com.
}

\begin{abstract}
One-lung ventilation (OLV) is an anesthesiological procedure used to facilitate thoracic surgery; sometimes OLV is an absolute indication, and it's indispensable for a safe and effective surgery on the lung's parenchyma. In patients with anticipated difficult airways, the insertion of a double-lumen tube (DLT), the actual standard of care for OLV, is less feasible and has some disadvantages and could even be dangerous or not feasible. In these circumstances, Bronchial Blockers (BB) are a viable option; among BB, EZ-blocker (EZB)'s use can be considered appropriate. We present a case where tracheostomy, respiratory distress due to post-traumatic air leaks, and the need to allow the surgeon to identify and reach the lung's lesions intraoperative required selective and sequential ventilation of the superior and lower left lobe. Selective and sequential lobar ventilation was performed with the EZB, positioned by endoscopic guidance through the tracheotomy tube, enabling the identification and the suture of pulmonary lesions allowing optimum oxygenation. According to our preliminary experience, EZB represents an opportunity for selective lobar exclusion in which it is necessary to alternate the exclusion of different lung lobes, especially on the left side. More data are needed to evaluate this approach.
\end{abstract}

Keywords: EZ-blocker (EZB); one-lung ventilation (OLV); difficult airway; case report

Received: 24 October 2019; Accepted: 18 December 2019; Published: 25 May 2020.

doi: $10.21037 /$ ccts.2019.12.09

View this article at: http://dx.doi.org/10.21037/ccts.2019.12.09

\section{Introduction}

One-lung ventilation (OLV) is an anesthesiological technique used in thoracic surgery. Endobronchial blocker is an efficient alternative for OLV in patients with a difficult airway or tracheostomy. EZ-blocker (EZB) is a Y shape semi-rigid endobronchial blocker with two distal extensions, both with inflatable color-coded cuffs, to achieve OLV (1). Rispoli et al. described that the EZB can be used via tracheostomy (2). The case is presented in accordance with the CARE guideline.

\section{Case presentation}

We report a case of 51-year-old man involved in a high impact road accident. Orotracheal intubation was performed and he was admitted at the emergency department of our hospital (Figure 1). CT total body was performed and showed: subdural hematoma in left front parietal region, IV-VII rib fractures, diaphragmatic rupture and herniation of the stomach into the thoracic cavity, hemothorax and left basal pulmonary contusion. He underwent laparoscopicassisted right hemicolectomy and cholecystectomy. The patient was subsequently transported to intensive care unit (ICU) for acute respiratory failure, $(\mathrm{P} / \mathrm{F}=70)$, intubated with selective lung ventilation through tracheostomy. A thorax CT scan showed hydropneumothorax, treated by the placement of two chest tubes (anterior and posterior) in ICU. Due to continuous air leak and without evidence 


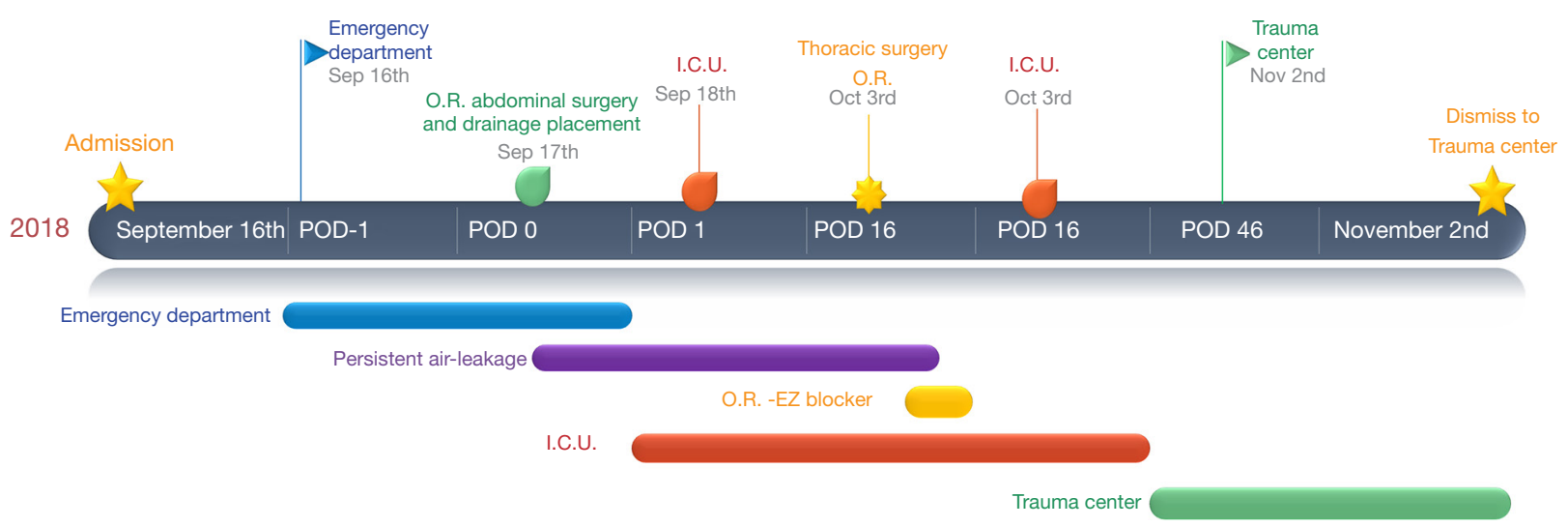

Figure 1 Historical and current information from this episode of care organized as timeline. ICU, intensive care unit; POD, postoperative day.

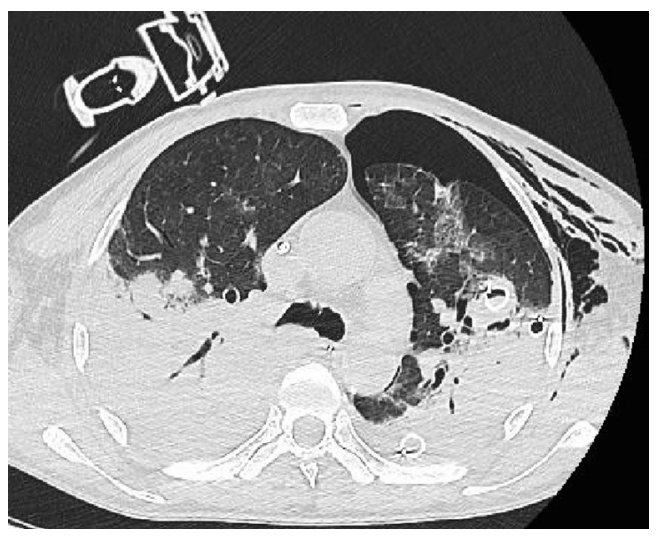

Figure 2 Chest CT scan.

of site lesion on CT, an exploratory thoracotomy in order to perform the direct suture of the probable pulmonary lesions was planned (Figure 2). Preoperative esophagogastric adenocarcinoma (EGA): $\mathrm{pH} 7.33, \mathrm{pCO}_{2} 72 \mathrm{mmHg}$, $\mathrm{P} / \mathrm{F}=69$. Due to worsening respiratory distress and the need of OLV, we decided to change over double-lumen tube (DLT) to single lumen tube $(8 \mathrm{~mm})$ and use the EZB placed in the left airways to achieve lobar selective ventilation. We had set up veno-venous extracorporeal membrane oxygenation (VV-ECMO) as rescue therapy. The EZB was advanced under fiber-optic guidance (flexible scope $\mathrm{Ambu}^{\circledR}$ aScope $^{\mathrm{TM}} 4$ Broncho Slim 3.8/1.2) into the tracheostomy tube until the secondary carina of left mainstem bronchus was visualized. Then the cuff was alternative inflated to achieve selective and sequential ventilation of superior and lower left lobe. This allowed the surgeon to reach the

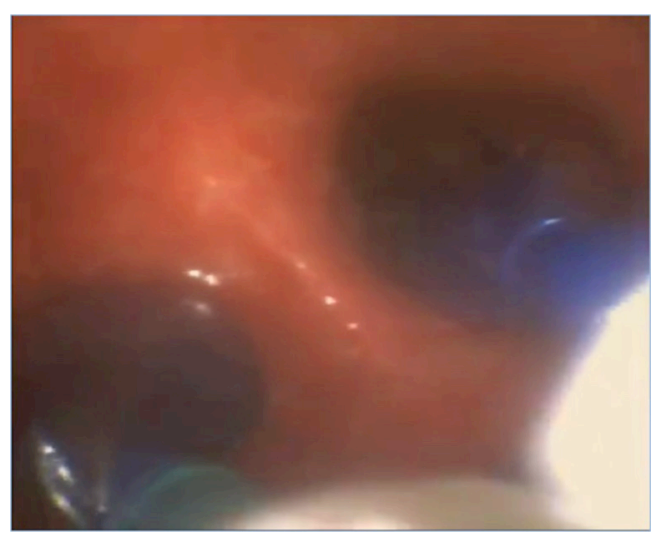

Figure 3 Intraoperative photograph of selective lobar exclusion.

lesions intraoperative (Figure 3). The selective ventilation was optimal and the EZB didn't dislocate during the surgical procedure. After identifying pulmonary lesions (two anterior and one posterior on the left superior lobe), the suture of lung lacerations was made. The patients had stable hemodynamic, $\mathrm{SpO}_{2}$ 96\%, EGA: $\mathrm{pH} 7.36, \mathrm{pCO}_{2} 72 \mathrm{mmHg}$, $\mathrm{pO}_{2} 86 \mathrm{mmHg}$. After removing the EZB at the end of surgery, the lung recruitment maneuvers were performed, and the patient was admitted to ICU $(\mathrm{P} / \mathrm{F}=180)$.

All procedures performed in this study were in accordance with the ethical standards of the institutional and national research committees and with the Helsinki Declaration (as revised in 2013). Written informed consent was obtained from the patient for publication of this case report and any accompanying images. A copy of the written consent is available for review by the editorial office of this journal. 


\section{Discussion and conclusions}

To the best of our knowledge, this is the first report describing use of EZB for selective and sequential lobar exclusion. EZB feature simplifies its placement into the 2 -stem bronchus, and as with the present case into the superior and lower left lobe. A fiber-optic bronchoscope is used to identify the correct placement of the EZB.

The use of the EZB allows overcoming DLT and bronchial blocking (BB) devices difficulties. In particular, the DLT is larger compared to EZB, the incidence of postoperative hoarseness and airway injuries is higher, and its introduction can be sometimes difficult or even impossible to achieve (3). On the other hand, the $\mathrm{BB}$ devices are more difficult to position and more frequently need intraoperative repositioning even if are commonly used in patients with difficult airways (4). EZB was used to achieve OLV in patients undergoing elective thoracic surgery, either thoracotomy or video-assisted thoracoscopic surgery (VATS) $(3,5)$ and tracheal surgery (6). Rispoli et al. showed a shallow learning curve, the $100 \%$ of successful rate of positioning EZB was obtained after the nine attempts (4).

Definitively, EZB can be an effective option to achieve selective and sequential exclusion in patients with lower breathing reserve. Moreover, EZB allow a safe OLV in patients with a predicted difficult intubation. As demonstrated by this case report, it is also an attractive approach for the management of airways when it is not possible to detect preoperatively lesion's site. In this case, VV-ECMO could be considered as a viable rescue therapy.

\section{Acknowledgments}

Funding: None.

\section{Footnote}

Conflicts of Interest: All authors have completed the ICMJE uniform disclosure form (available at https://ccts. amegroups.com/article/view/10.21037/ccts.2019.12.09/ coif). The authors have no conflicts of interest to declare.

Ethical Statement: The authors are accountable for all aspects of the work in ensuring that questions related to the accuracy or integrity of any part of the work are appropriately investigated and resolved. All procedures performed in this study were in accordance with the ethical standards of the institutional and national research committees and with the Helsinki Declaration (as revised in 2013). Written informed consent was obtained from the patient for publication of this case report and any accompanying images. A copy of the written consent is available for review by the editorial office of this journal.

Open Access Statement: This is an Open Access article distributed in accordance with the Creative Commons Attribution-NonCommercial-NoDerivs 4.0 International License (CC BY-NC-ND 4.0), which permits the noncommercial replication and distribution of the article with the strict proviso that no changes or edits are made and the original work is properly cited (including links to both the formal publication through the relevant DOI and the license). See: https://creativecommons.org/licenses/by-nc-nd/4.0/.

\section{References}

1. Moritz A, Irouschek A, Birkholz T, et al. The EZ-blocker for one-lung ventilation in patients undergoing thoracic surgery: clinical applications and experience in 100 cases in a routine clinical setting. J Cardiothorac Surg 2018;13:77.

2. Rispoli M, Nespoli MR, Salvi R, et al. One-lung ventilation in tracheostomized patients: our experience with EZ-Blocker. J Clin Anesth 2016;31:288-90.

3. Mungroop HE, Wai PT, Morei MN, et al. Lung isolation with a new Y-shaped endobronchial blocking device, the EZ-Blocker ${ }^{\circledR}$. British Journal of Anaesthesia 2010;104:119-20.

4. Rispoli M, Zani G, Bizzarri F, et al. Bronchial blocker positioning: learning curve and confidence in its use. Minerva Anestesiol 2018;84:1254-60.

5. Mungroop H, Loef B, Huyzen R, et al. A novel method of lung isolation using a new bronchial blocking device: 19AP7-7. Eur J Anaesthesiol 2008;25:255.

6. Rispoli M, Nespoli MR, De Simone MG, et al. EZblocker in tracheal surgery. J Cardiothorac Vasc Anesth 2015;29:e89-90.

doi: $10.21037 /$ ccts.2019.12.09

Cite this article as: Galatà $\mathrm{M}$, Lyberis $\mathrm{P}$, Bisciaio A, Ceraolo E, Rosboch GL, Ruffini E, Guerrera F. The efficacy of endobronchial blocker "EZ-blocker" for selective lobar ventilation: case report. Curr Chall Thorac Surg 2020;2:19. 